\title{
Clinical utility gene card for: Prader-Willi Syndrome
}

\author{
Karin Buiting ${ }^{\star, 1}$, Suzanne B Cassidy ${ }^{2}$, Daniel J Driscoll ${ }^{3}$, Gabriele Gillessen-Kaesbach ${ }^{4}$, Deniz Kanber ${ }^{1}$, \\ Maithé Tauber ${ }^{5,6}$, Eberhard Schwinger ${ }^{4}$ and Bernhard Horsthemke ${ }^{1}$
}

European Journal of Human Genetics (2014) 22, doi:10.1038/ejhg.2014.66; published online 16 April 2014

\section{DISEASE CHARACTERISTICS}

1.1 Name of the disease (synonyms)

Prader-Willi Syndrome (PWS).

\subsection{OMIM\# of the disease}

176270 .

1.3 Name of the analysed genes or DNA/chromosome segments SNURF-SNRPN/\#15q11-q13.

\subsection{OMIM\# of the gene(s)}

182279.

\subsection{Mutational spectrum}

$70-75 \%$ paternal de novo deletion $15 \mathrm{q} 11-\mathrm{q} 13$,

25-30\% maternal uniparental disomy 15 (upd(15)mat),

$1 \%$ imprinting defect,

Rare: balanced translocation with breakpoint in the SNURF-SNRPN

locus,

Rare: deletion of SNORD116

Data on this disease (gene variants/phenotype) can be found in the public database Decipher (https://decipher.sanger.ac.uk).

\subsection{Analytical methods}

DNA methylation-specific MLPA, DNA methylation-specific PCR, DNA methylation-specific pyrosequencing, microsatellite analysis, oligonucleotide chromosome microarray and oligonucleotide with SNP chromosome microarray (both with methylation analysis follow-up or concurrent testing if deletion present), FISH.

\subsection{Analytical validation}

Parallel analysis of negative and positive controls.

1.8 Estimated frequency of the disease (Incidence at birth ('birth prevalence') or population prevalence)

If known to be variable between ethnic groups, please report:

Prevalence at birth 1:10000 to 1:25000.

\subsection{Diagnostic setting:}

\begin{tabular}{lll}
\hline & Yes & No. \\
A. (Differential) diagnostics & $\bigotimes$ & $\square$ \\
B. Predictive testing & $\square$ & $\square$ \\
C. Risk assessment in relatives & $\bigotimes$ & $\square$ \\
D. Prenatal & $\bigotimes$ & $\square$ \\
\hline
\end{tabular}

Comment:

In cases with a 15q11-q13 de novo deletion or maternal uniparental disomy 15 , the recurrence risk is very low if parental chromosomes are normal. In $<1 \%$ deletion cases, the presence of a balanced parental chromosome 15 rearrangement confers a high risk of recurrence and should be excluded. The majority of patients with PWS and an imprinting defect are sporadic cases without any detectable mutations on the DNA sequence level. These imprinting defects usually do not show familial recurrence and therefore appear to be associated with a low recurrence risk. Approximately $10-15 \%$ of patients with an imprinting defect have a microdeletion of the chromosome 15 imprinting centre (IC). In $\sim 50 \%$ of cases the IC deletion was found to be a familial mutation associated with a $50 \%$ recurrence risk. In the remaining cases the IC deletion was de novo or a consequence of a germline mosaicism in the father. ${ }^{1-3}$

\section{TEST CHARACTERISTICS}

\begin{tabular}{|c|c|c|c|c|}
\hline & \multicolumn{2}{|c|}{ Genotype or disease } & \multirow{2}{*}{$\begin{array}{l}\text { A: True positives } \\
\text { B: False positives }\end{array}$} & \multirow{2}{*}{$\begin{array}{l}\text { C: False negatives } \\
\text { D: True negatives }\end{array}$} \\
\hline & Present & Absent & & \\
\hline \multicolumn{5}{|l|}{ Test } \\
\hline \multirow[t]{2}{*}{ Positive } & $A$ & $\mathrm{~B}$ & Sensitivity: & $A /(A+C)$ \\
\hline & & & Specificity: & $D /(D+B)$ \\
\hline \multirow[t]{2}{*}{ Negative } & C & $\mathrm{D}$ & Positive predictive value: & $A /(A+B)$ \\
\hline & & & Negative predictive value: & $D /(C+D)$ \\
\hline
\end{tabular}

\subsection{Analytical sensitivity}

(proportion of positive tests if the genotype is present)

Nearly $100 \%$.

\footnotetext{
${ }^{1}$ Institute of Human Genetics, University Hospital Essen, University Duisburg-Essen, Essen, Germany; ${ }^{2}$ Department of Pediatrics, Division of Medical Genetics, University of California, San Francisco, CA, USA; ${ }^{3}$ Division of Genetics and Metabolism, Department of Pediatrics, University of Florida College of Medicine, Gainesville, FL, USA; ${ }^{4}$ Institut für Humangenetik, Universität zu Lübeck, Lübeck, Germany; ${ }^{5}$ Centre de référence du syndrome de Prader-Willi, service d'endocrinologie, Hôpital des Enfants, CHU Toulouse, Toulouse, France; ${ }^{6}$ Centre de Physiopathologie de Toulouse Purpan, INSERM UMR 1043, Toulouse, France

*Correspondence: Dr K Buiting, Institute of Human Genetics, University Hospital Essen, Hufelandstrasse 55, 45122 Essen, Germany. Tel: +49 2017234555 ; Fax: +49 201 7235900; E-mail: karin.buiting@uni-due.de
}

Received 24 January 2014; revised 26 February 2014; accepted 18 March 2014 
2.2 Analytical specificity

(proportion of negative tests if the genotype is not present)

Nearly $100 \%$.

\subsection{Clinical sensitivity}

(proportion of positive tests if the disease is present)

The clinical sensitivity can be dependent on variable factors such as age or family history. In such cases a general statement should be given, even if a quantification can only be made case by case.

Nearly $100 \%$.

\subsection{Clinical specificity}

(proportion of negative tests if the disease is not present)

The clinical specificity can be dependent on variable factors such as age or family history. In such cases a general statement should be given, even if a quantification can only be made case by case.

Nearly $100 \%$.

2.5 Positive clinical predictive value

(life time risk to develop the disease if the test is positive) $100 \%$.

\subsection{Negative clinical predictive value}

(Probability not to develop the disease if the test is negative). Assume an increased risk based on family history for a non-affected person. Allelic and locus heterogeneity may need to be considered. Index case in that family had been tested:

Nearly $100 \%$.

Index case in that family had not been tested:

Can only be resolved by analysis of the non-affected individual.

\section{CLINICAL UTILITY}

3.1 (Differential) diagnostics: The tested person is clinically affected

(To be answered if in 1.9 'A' was marked)

\subsubsection{Can a diagnosis be made other than through a genetic test?}

$\begin{array}{ll}\text { No } & \bigotimes \text { (continue with 3.1.4) } \\ \text { Yes } & \square \\ & \text { Clinically } \\ & \text { Imaging } \\ & \text { Endoscopy } \\ & \text { Biochemistry } \\ & \text { Electrophysiology } \\ & \text { Other (please describe) }\end{array}$

Comment:

Many disorders can mimic parts of the PWS phenotype.

Infantile hypotonia is also seen in the following conditions: central and peripheral neuromuscular disorders (especially, spinal muscular atrophy), CNS anomalies, anoxia, some inborn errors, Angelman syndrome, fragile X syndrome and MECP2-related disorders.

Childhood-onset obesity with developmental delay is also present in Bardet-Biedl syndrome, Alstrom syndrome, Borjeson-ForssmanLehman syndrome, Cohen syndrome, Fragile X syndrome (there is a subtype with hyperphagia and obesity) and deletion 16p11.2 (includes $\mathrm{SH} 2 \mathrm{~B} 1$, which is involved in leptin and insulin signalling).

Generally, similar phenotype is seen in patients with maternal uniparental disomy 14, an epimutation or a paternal deletion of the $14 \mathrm{q} 32$ imprinted region (upd(14)mat syndrome or Temple syndrome) and chromosomal disorders (deletion 1p36, deletion 6q16.2, deletion 10q26, duplication 3p25.3-26.2, duplication Xq27.2-ter).

\subsubsection{Describe the burden of alternative diagnostic methods to the} patient

3.1.3 How is the cost effectiveness of alternative diagnostic methods to be judged?

3.1.4 Will disease management be influenced by the result of a genetic test?

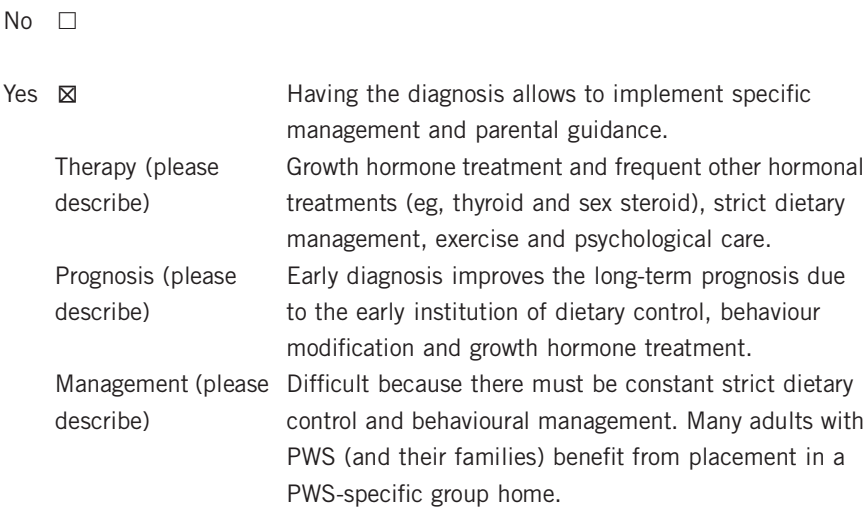

3.2 Predictive setting: The tested person is clinically unaffected but carries an increased risk based on family history

(To be answered if in 1.9 'B' was marked)

3.2.1 Will the result of a genetic test influence lifestyle and prevention?

If the test result is positive (please describe).

If the test result is negative (please describe).

3.2.2 Which options in view of lifestyle and prevention does a person at-risk have if no genetic test has been done (please describe)?

3.3 Genetic risk assessment in family members of a diseased person (To be answered if in 1.9 'C' was marked)

3.3.1 Does the result of a genetic test resolve the genetic situation in that family?

A proven IC deletion could lead, to some extent, to resolve the genetic situation in a family regarding the inheritance pattern.

3.3.2 Can a genetic test in the index patient save genetic or other tests in family members?

No.

3.3.3 Does a positive genetic test result in the index patient enable a predictive test in a family member?

No.

3.4 Prenatal diagnosis

(To be answered if in 1.9 'D' was marked) 
3.4.1 Does a positive genetic test result in the index patient enable a prenatal diagnosis?

Yes.

\section{IF APPLICABLE, FURTHER CONSEQUENCES OF TESTING}

Please assume that the result of a genetic test has no immediate medical consequences. Is there any evidence that a genetic test is nevertheless useful for the patient or his/her relatives? (Please describe)

For the parents the result conveys clarity about the eventual cause of the disease.

It may bring relief from own feelings of guilt. The genetic type is important for genetic counselling regarding the recurrence of the disease.

A positive test is prerequisite for growth hormone therapy.

\section{CONFLICT OF INTEREST}

The authors declare no conflict of interest.

\section{ACKNOWLEDGEMENTS}

This work was supported by EuroGentest2 (Unit 2: 'Genetic testing as part of health care'), a Coordination Action under FP7 (Grant Agreement Number 261469) and the European Society of Human Genetics. KB, GG-K and BH are supported by the German Ministry of education and sciences BMBF (Network 'Imprinting Diseases', 01GM1114), GG-K, MT and BH are members of the COST Action BM1208.

1 Cassidy SB, Schwartz S, Miller JL, Driscoll DJ: Prader-Willi syndrome. Genet Med 2012; 14: 10-26.

2 Ramsden SC, Clayton-Smith J, Birch R, Buiting K: Practice guidelines for the molecular analysis of Prader-Willi and Angelman syndromes. BMC Med Genet 2010; 11: 11-70.

3 Buiting K: Prader-Willi syndrome and Angelman syndrome. Am J Med Genet Part C 2010; 154C: 365-376. 